\title{
Outcomes following discectomy for lumbar disc herniation in patients with substantial back pain
}

\author{
Simon Thorbjørn Sørensen, MD, ${ }^{1}$ Rachid Bech-Azeddine, MD, PhD, ${ }^{2}$ Søren Fruensgaard, MD, ${ }^{3}$ \\ Mikkel Østerheden Andersen, MD, ${ }^{1}$ and Leah Carreon, MD'1 \\ ${ }^{1}$ Center for Spine Surgery \& Research, Middelfart Hospital, Middelfart; ${ }^{2}$ Center for Rheumatology and Spine Diseases, \\ Rigshospitalet-Glostrup; and ${ }^{3}$ Department of Orthopaedic Surgery, Regionshospitalet Silkeborg, Denmark
}

\begin{abstract}
OBJECTIVE Patients with lumbar disc herniation (LDH) typically present with lower-extremity radiculopathy. However, there are patients who have concomitant substantial back pain (BP) and are considered candidates for fusion. The purpose of this study was to determine if patients with LDH and substantial BP improve with discectomy alone.

METHODS The DaneSpine database was used to identify 2399 patients with LDH and baseline BP visual analog scale (VAS) scores $\geq 50$ who underwent a lumbar discectomy at one of 3 facilities between June 2010 and December 2017. Standard demographic and surgical variables and patient-reported outcomes, including BP and leg pain (LP) VAS scores (0-100), Oswestry Disability Index (ODI), and European Quality of Life-5 Dimensions Questionnaire (EQ-5D) at baseline and 12 months postoperatively, were collected.
\end{abstract}

RESULTS A total of 1654 patients (69\%) had 12-month data available, with a mean age of 48.7 years; 816 (49\%) were male and the mean BMI was $27 \mathrm{~kg} / \mathrm{m}^{2}$. At 12 months postoperatively, there were statistically significant improvements ( $p$ $<0.0001)$ in BP (72.6 to 36.9), LP (74.8 to 32.6), ODI (50.9 to 25.1), and EQ-5D (0.25 to 0.65) scores.

CONCLUSIONS Patients with LDH and LP and concomitant substantial BP can be counseled to expect improvement in their BP 12 months after surgery after a discectomy alone, as well as improvement in their LP.

https://thejns.org/doi/abs/10.3171/2020.4.SPINE191382

KEYWORDS back pain; leg pain; discectomy; lumbar disc herniation; patient-reported outcomes

$\mathrm{L}$ UMBAR disc herniation (LDH) is a common disease with a prevalence of $2 \%-3 \%$, and the highest incidence for men in the 4th to 5th decade of life. ${ }^{1}$ LDH traditionally presents with radicular pain in the lower extremities, also known as sciatica, but can also cause lowback pain (LBP). Most patients with LDH can be treated nonsurgically. Nonoperative treatment normally includes analgesics, physiotherapy, chiropractic manipulation, and, at certain facilities, epidural steroid injections. ${ }^{2}$ In some cases, surgery is indicated due to neurological deficit, untenable pain and disability, or unsuccessful conservative treatment.

Surgery for LDH is common, accounting for approximately one-third of the spine surgeries performed annually in Denmark. ${ }^{3}$ In the 1930 s, Mixter stated that discectomy should be combined with fusion to strengthen an already weakened spine. ${ }^{4}$ This has been challenged by a few studies, the largest being the Spine Patient Outcomes Research Trial (SPORT) with 743 patients, and found that discectomy alone is an effective treatment of back pain (BP) caused by LDH. ${ }^{5}$ Kuslich et al. ${ }^{6}$ tried to define the origin of LBP and sciatica in 1991 with the use of local anesthesia in 193 patients with LDH. They proposed that leg pain (LP) originated from an affected nerve root and LBP came from the posterior portion of the intervertebral disc. This finding provides the theoretical rationale for performing a discectomy alone without the need for a fusion.

The aim of this study was to evaluate the effectiveness of discectomy alone for patients with LDH, LP, and substantial BP in a pragmatic study of patients prospectively enrolled in the DaneSpine Database.

ABBREVIATIONS BP = back pain; EQ-5D = European Quality of Life-5 Dimensions Questionnaire; LBP = low-back pain; LDH = lumbar disc herniation; LP = leg pain; MCID = minimal clinically important difference; ODI = Oswestry Disability Index; PRO = patient-reported outcome; SCB = substantial clinical benefit; SPORT = Spine Patient Outcomes Research Trial; VAS = visual analog scale.

SUBMITTED November 27, 2019. ACCEPTED April 22, 2020.

INCLUDE WHEN CITING Published online July 10, 2020; DOI: 10.3171/2020.4.SPINE191382. 
TABLE 1. Patient demographics

\begin{tabular}{lc}
\hline \multicolumn{1}{c}{ Variable } & Value \\
\hline No. of patients & 1654 \\
\hline Mean age $\pm \mathrm{SD}$, yrs & $48.75 \pm 14.66$ \\
\hline Males & $816(49.3 \%)$ \\
\hline Smokers & $556(33.6 \%)$ \\
\hline Mean BMI $\pm \mathrm{SD}, \mathrm{kg} / \mathrm{m}^{2}$ & $26.91 \pm 4.71$ \\
\hline
\end{tabular}

\section{Methods}

\section{Study Population}

This study included patients with LDH treated with a discectomy at one of 3 Danish Spine units (Center for Spine Surgery \& Research, Middelfart Hospital; Center for Rheumatology and Spine Diseases, Rigshospitalet-Glostrup; and Department of Orthopaedic Surgery, Regionshospitalet Silkeborg) between June 2010 and December 2017. All patients were treated following the Danish national guidelines for treatment of $\mathrm{LDH}$, which include physiotherapy, low-back specific exercises, and in some cases steroid injections. ${ }^{8}$ In cases of unsuccessful conservative treatment, the patients were referred to a spine specialist along with MRI. All patients who were offered surgery had an MR image concordant with the clinical findings and, in general, at least 12 weeks of symptom duration, despite conservative treatment. The primary indication for surgery was LP.

\section{Data Collection}

The data was collected through the DaneSpine database, the national spine surgery database in Denmark. Therefore, this was a retrospective longitudinal study using prospectively collected data, including patient-reported outcomes (PROs) preoperatively and at 12 months postoperatively. The questions include data on age, sex, height, weight, smoking status, BP visual analog scale (VAS) score (0-100), LP VAS score (0-100), ${ }^{9}$ Oswestry Disability Index (ODI), ${ }^{10}$ and European Quality of Life-5 Dimensions Questionnaire (EQ-5D). ${ }^{11}$

\section{Statistical Analyses}

Only patients with LP and BP VAS scores of 50 points or greater at baseline were included. The threshold of $\geq 50$ points of 100 total BP VAS points was selected to capture patients whose BP was an important contributor to their symptomatology..$^{12}$ All statistical analyses were performed using the SPSS statistical program (version 25.0, IBM Corp.). Baseline PROs were compared to 12-month PROs using paired t-tests.

\section{Results}

A total of 4426 patients were treated with a discectomy and had at least 1 year of follow-up. Of these 4426 patients, 2399 had a preoperative BP VAS score $\geq 50$, and 1654 of these patients (69\%) answered the 1-year followup questionnaires. The mean patient age was $48.75 \pm 14.66$ years at the day of operation: $816(49.3 \%)$ were men, 556
TABLE 2. Comparison between baseline and 1-year follow-up measures

\begin{tabular}{lccc}
\hline \multicolumn{1}{c}{ Outcome Measure } & Baseline (SD) & $\begin{array}{c}\text { 1-Yr Follow- } \\
\text { Up (SD) }\end{array}$ & p Value \\
\hline Mean BP VAS (SD), 0-100 & $72.57(14.23)$ & $36.92(29.61)$ & $<0.0001$ \\
\hline Mean LP VAS (SD), 0-100 & $74.82(18.48)$ & $32.63(31.15)$ & $<0.0001$ \\
\hline Mean ODI (SD), 0-100 & $50.94(17.33)$ & $25.07(19.10)$ & $<0.0001$ \\
\hline Mean EQ-5D (SD), 0-1.0 & $0.25(0.33)$ & $0.65(0.31)$ & $<0.0001$ \\
\hline
\end{tabular}

(33.6\%) were smokers, and the average BMI was $26.91 \pm$ $4.71 \mathrm{~kg} / \mathrm{m}^{2}$ (Table 1$)$.

At the 1-year follow-up, the BP VAS score improved from 72.57 to 36.92 and the LP VAS score reduced from 74.82 to 32.63 . The ODI improved from 50.94 to 25.07 , and the EQ-5D score increased from 0.25 to 0.65 . All these results were statistically significant (Table 2).

Regarding BP VAS scores, a minimal clinically important difference (MCID) was achieved by $75.9 \%$ of the patients, and $62.5 \%$ achieved substantial clinical benefit (SCB). Concerning LP VAS, 71.0\% achieved MCID and $66.3 \%$ SCB. MCID and SCB were $70.3 \%$ and $61.2 \%$, respectively, regarding the ODI (Table 3). Baseline variables in responders and nonresponders were analyzed and did not show any statistically significant differences (Table 4).

Two hundred seven patients required a reoperation in the follow-up period. These reoperations included discectomy due to recurrent disc herniation $(n=161)$, repeat decompression $(n=28)$, evacuation of hematoma $(n=10)$, infection $(n=4)$, fusion $(n=2)$, and dural tear repair $(n=2)$.

\section{Discussion}

This study showed statistically and clinically significant $^{10,13,14}$ improvements in self-reported BP, LP, mobility, and quality of life in patients with LDH and substantial BP after discectomy surgery without fusion. These findings are consistent with the most influential studies on this field: the Weber cohort,$^{15}$ the Maine Lumbar Spine Study by Atlas et al., ${ }^{16,17}$ and the SPORT cohort by Weinstein et al. ${ }^{5}$ Both the Weber and Atlas studies had 10 years of follow-up, with statistically significant improvements in BP 1 year postoperatively. These improvements persisted during the follow-up, although at 10 years they were no longer statistically significant (but a tendency remained). Patients in the SPORT observational cohort had 2 years of followup, showing statistically significant improvements during the entire follow-up period. These results converged over time, which is in accordance with the tendency in the Weber and Maine studies. A recent longitudinal observational cohort study by Owens and colleagues ${ }^{18}$ involved 2262 patients with a preoperative BP VAS score $\geq 50$, who were treated with 1- or 2-level discectomy without fusion, and showed similar outcomes.

A prospective study by Sun et al. ${ }^{19}$ compared decompression alone versus decompression with fusion. They found no significant differences at the 1-year follow-up between the two groups, but at 3 and 6 months, there were significantly better improvements in LBP for the decompression-alone group. Physical function according to the 
TABLE 3. Patients achieving MCID and SCB

\begin{tabular}{ccc}
\hline Outcome Measure & MCID (\%) & SCB (\%) \\
\hline BP VAS & 75.9 & 62.5 \\
\hline LP VAS & 71.0 & 66.3 \\
\hline ODI & 70.3 & 61.2 \\
\hline
\end{tabular}

Japanese Orthopaedic Association scale showed significantly better results after 3 months for the decompressionalone group. At 1-year follow-up, the results were similar for the two groups. Therefore, patients were able to achieve greater physical function and pain relief earlier with only a decompression procedure.

Our study has a few limitations, including the lack of a control group. This makes us unable to comment on the spontaneous improvement in this cohort, despite the fact that all the patients underwent conservative treatment prior to surgery. The natural course of LDH has a good prognosis, and patients can expect substantial improvement over a 2-year period. ${ }^{20}$ The relatively short follow-up period, and lack of additional data within the first year, prevent us from being able to evaluate whether the improvements persist over time.

The impact on the length of symptoms prior to surgery was not evaluated in this study. A recent study by Støttrup et al. ${ }^{21}$ found that prolonged duration of preoperative symptoms resulted in an inferior outcome. The optimal window to perform the operation should be between 3 and 12 months after first detecting symptoms, and prolonged preoperative symptoms increase the risk of reoperation.

There are many different surgical techniques to decompress the nerve root, which have an impact on the postoperative backache secondary to muscle dissection and bone excision. All patients treated at our facilities received either an open discectomy or microdiscectomy. The surgical technique chosen is determined by the operating surgeon at each facility and depends on the location of the LDH and any associated pathologies. Whichever surgical technique is selected, the main goal with the surgery is to decompress the affected nerve root to ease the patient's radicular pain and improve neurological function. The operational technique was not examined in this study.

Approximately one-third of the patients did not complete the 1-year PROs. This dropout rate might lead to a distortion of the results. A dropout analysis by Højmark et al. ${ }^{7}$ using the DaneSpine database did not show any bias in the conclusions of the study. The nonresponders were generally younger men, and too busy with work and family responsibilities. Furthermore, the nonresponders demonstrated better improvement of health-related quality of life as measured on the EQ-5D compared to the responders. The responders and nonresponders in our study did not show any differences in baseline variables (Table 4). Therefore, the high dropout rate might have only a minor influence on the outcome, despite the fact that a lack of complete follow-up is a possible source of bias.

The strengths of this study are the large population studied, the fact that it was a multicenter trial at 3 facilities, and that the data were collected prospectively even
TABLE 4. Baseline variables for responders and nonresponders

\begin{tabular}{lccc}
\hline \multicolumn{1}{c}{ Variable } & Responders & Nonresponders & $\mathrm{p}$ Value \\
\hline No. of patients & 1654 & 745 & \\
\hline Mean age (SD), yrs & $48.75(14.66)$ & $48.34(14.22)$ & 0.345 \\
\hline Males & 816 & 353 & 0.377 \\
\hline Smokers & 556 & 222 & 0.072 \\
\hline Mean BMI (SD), kg/m² & $26.91(4.71)$ & $26.93(4.79)$ & 0.894 \\
\hline Mean BP VAS (SD), 0-100 & $72.57(14.23)$ & $72.89(14.04)$ & 0.692 \\
\hline Mean LP VAS (SD), 0-100 & $74.82(18.48)$ & $74.24(19.50)$ & 0.431 \\
\hline Mean ODI (SD), 0-100 & $50.94(17.33)$ & $49.21(17.60)$ & 0.652 \\
\hline Mean EQ-5D (SD), 0-1.0 & $0.25(0.33)$ & $0.23(0.32)$ & 0.0531 \\
\hline
\end{tabular}

though they were evaluated retrospectively. All these strengths reduce the risk of bias and make the results more reproducible.

Because decompression without fusion involves a shorter surgical duration, less blood loss, a shorter hospital stay, and lower costs,$^{19}$ a discectomy should be the first option in patients with LDH, unless a facet resection is necessary as in cases of foraminal or extraforaminal herniations. ${ }^{18}$

\section{Conclusions}

This present study adds to the evidence that a discectomy without fusion in patients with LDH, LP, and substantial BP is an appropriate treatment and can produce improvements in BP, LP, mobility, and quality of life, without the need for a concomitant fusion.

\section{References}

1. Vialle LR, Vialle EN, Suárez Henao JE, Giraldo G. Lumbar disc herniation. Rev Bras Ortop. 2015;45(1):17-22.

2. Andersen M $\varnothing$, Andresen AK, Lorenzen MD, et al. Non-surgical treatment of lumbar radiculopathy. Article in Danish. Ugeskr Laeger. 2017;179(23):V05170397.

3. Andersen M, Nielsen M, Bech-Azeddine R, et al. Rygkirurgi Årsrapport 2017. Dansk Rygkirurgisk Selskab; 2018. Accessed May 7, 2020. http://drksdanespine.dk/dwn674620

4. Mixter WJ. Rupture of the lumbar intervertebral disk: an etiologic factor for so-called "sciatic" pain. Ann Surg. 1937;106(4):777-787.

5. Weinstein JN, Lurie JD, Tosteson TD, et al. Surgical vs nonoperative treatment for lumbar disk herniation: the Spine Patient Outcomes Research Trial (SPORT) observational cohort. JAMA. 2006;296(20):2451-2459.

6. Kuslich SD, Ulstrom CL, Michael CJ. The tissue origin of low back pain and sciatica: a report of pain response to tissue stimulation during operations on the lumbar spine using local anesthesia. Orthop Clin North Am. 1991;22(2):181-187.

7. Højmark K, Støttrup C, Carreon L, Andersen MO. Patientreported outcome measures unbiased by loss of follow-up. Single-center study based on DaneSpine, the Danish spine surgery registry. Eur Spine J. 2016;25(1):282-286.

8. Junker K, Kongsted A, Fournier G, et al. National klinisk retningslinje for ikke-kirurgisk behandling af nylig opstået lumbal nerverodspåvirkning (lumbal radikulopati). Sundhedsstyrelsen; 2016. Accessed May 7, 2020. https://www.sst. dk/da/udgivelser/2016/ /media/2F85F728D715400AB004C5 9C8E2C7937.ashx 
9. Karcioglu O, Topacoglu H, Dikme O, Dikme O. A systematic review of the pain scales in adults: Which to use? Am J Emerg Med. 2018;36(4):707-714.

10. Fairbank JC, Pynsent PB. The Oswestry Disability Index. Spine (Phila Pa 1976). 2000;25(22):2940-2952.

11. EuroQol Group. EuroQol-a new facility for the measurement of health-related quality of life. Health Policy. 1990;16(3):199-208.

12. Hayward M. Pain: clinical manual for nursing practice. Nurs Stand. 1994;9(11):55.

13. Coretti S, Ruggeri M, McNamee P. The minimum clinically important difference for EQ-5D index: a critical review. Expert Rev Pharmacoecon Outcomes Res. 2014;14(2):221-233.

14. Glassman SD, Copay AG, Berven SH, et al. Defining substantial clinical benefit following lumbar spine arthrodesis. $J$ Bone Joint Surg Am. 2008;90(9):1839-1847.

15. Weber H. Lumbar disc herniation. A controlled, prospective study with ten years of observation. Spine (Phila Pa 1976). 1983;8(2):131-140.

16. Atlas SJ, Keller RB, Wu YA, et al. Long-term outcomes of surgical and nonsurgical management of sciatica secondary to a lumbar disc herniation: 10 year results from the Maine Lumbar Spine Study. Spine (Phila Pa 1976). 2005;30(8):927935.

17. Atlas SJ, Deyo RA, Keller RB, et al. The Maine Lumbar Spine Study, Part II. 1-year outcomes of surgical and nonsurgical management of sciatica. Spine (Phila Pa 1976). 1996;21(15):1777-1786.

18. Owens RK II, Carreon LY, Bisson EF, et al. Back pain improves significantly following discectomy for lumbar disc herniation. Spine J. 2018;18(9):1632-1636.

19. Sun Z, Li W, Chen Z, et al. Decompression alone versus decompression with instrumented fusion for young patients with single-level lumbar disc herniation: a shortterm prospective comparative study. Chin Med J (Engl). 2014;127(11):2037-2042.

20. Weinstein JN, Tosteson TD, Lurie JD, et al. Surgical vs nonoperative treatment for lumbar disk herniation: the Spine Patient Outcomes Research Trial (SPORT): a randomized trial. JAMA. 2006;296(20):2441-2450.

21. Støttrup CC, Andresen AK, Carreon L, Andersen MO. Increasing reoperation rates and inferior outcome with prolonged symptom duration in lumbar disc herniation surgery-a prospective cohort study. Spine J. 2019;19(9):14631469.

\section{Disclosures}

Dr. Carreon reports being an employee of Norton Healthcare; being a consultant to the National Spine Health Foundation; reports that the Spine Center of Southern Denmark has received financial support from Hospital Lillebaelt Research Committee, Hospital Lillebaelt Development Committee, SDU faculty scholarship, Gangstedsfonden, The Danish Rheumatism Association, Region Syddanmarks Ph.D. Fund, Region Syddanmarks Research Funds, Region Sjælland and Region Syddanmarks common research funds, The Free Research Council, The A.P. Møller Fund of Advanced Medicine, Inger Goldmanns Fund, IMK Almene Fund, Aase and Ejnar Danielsens Fund, Overlæge Jørgen Werner Schous og hustru, Else-Marie Schou, født Wonge's Fund, Cerapedics, The Fund of Advanced Chiropractic Research and Postgraduate Education, Eli Lilly, Kroghs Donation, Ortotech, Guildal Foundation, and Janssen-Cilag A/S; and being a member of the Editorial Advisory Board for Spine Deformity, The Spine Journal, and Spine, and a member of the University of Louisville IRB.

\section{Author Contributions}

Conception and design: Andersen, Carreon. Acquisition of data: Bech-Azeddine, Fruensgaard, Andersen. Analysis and interpretation of data: Sørensen, Carreon. Drafting the article: Sørensen. Critically revising the article: all authors. Reviewed submitted version of manuscript: all authors. Approved the final version of the manuscript on behalf of all authors: Sørensen. Statistical analysis: Carreon.

\section{Supplemental Information \\ Previous Presentations}

This work was previously presented orally at the Danish Spine Society Annual Meeting, May 24, 2019, in Kolding, Denmark; as a poster at the Danish Orthopaedic Society Annual Meeting, October 23-25, 2019, in Kolding, Denmark; orally at the 34th North American Spine Society Annual Meeting, September 25-28, 2019, in Chicago, Illinois; and as an E-poster at the 26th International Meeting on Advanced Spine Techniques, July 17-20, 2019, in Amsterdam, The Netherlands.

\section{Correspondence}

Simon Thorbjørn Sørensen: Center for Spine Surgery \& Research, Middelfart Hospital, Middelfart, Denmark. simonthorbjorn@ gmail.com. 